\title{
A motivação como prevenção da indisciplina
}

\section{Motivation as indiscipline prevention}

\author{
Simone Deperon Eccheli*
}

\begin{abstract}
RESUMO
A autora considera que a indisciplina presente nas salas de aula pode estar sinalizando a falta de motivação dos alunos diante dos conteúdos acadêmicos, metodologias de ensino que não favorecem a aprendizagem significativa ou dificuldades na relação professor-aluno. A motivação do aluno para aprender é caracterizada de duas formas: como um traço geral (motivação intrínseca), ou como um estado situacional (motivação extrínseca). A autora diferencia as características dos alunos motivados e dos desmotivados em relação à aprendizagem escolar e oferece sugestões de ações para o professor organizar a situação de aprendizagem e influenciar positivamente o nível de motivação dos alunos nas atividades propostas.
\end{abstract}

Palavras-chave: indisciplina; motivação; relação professor-aluno.

\begin{abstract}
The author considers that the indiscipline present in the classrooms may indicate the students' lack of motivation of academic contents, teaching methodologies that don't benefit the significant learning or difficulties in the teacher-student relation. Student's learning motivation is characterized in two forms: as a general aspect (intrinsic motivation), or as a situational condition (extrinsic motivation). The author differentiates the characteristics of motivated students and of those unfounded students regarding to the school learning and offers actions suggestions for the teacher to organize the learning situation and to influence positively the students' motivation level in the proposed activities.

* Mestre em Análise do Comportamento. Psicóloga Escolar da Universidade Tecnológica Federal do Paraná - Campus Cornélio Procópio e Docente da Faculdade de Filosofia, Ciências e Letras de Cornélio Procópio.prsimonepr@yahoo.com.br
\end{abstract}


Keywords: indiscipline; motivation; teacher-student relation.

A importância da motivação nas atividades de ensino tem sido reforçada por pedagogos e psicólogos e o seu estudo pelo educador representa uma necessidade amplamente reconhecida, principalmente em escolas democráticas, nas quais os conteúdos e os métodos da educação devem, sempre que possível, respeitar as características individuais dos alunos.

Todas as teorias que procuram explicar o processo de motivação partem do princípio de que existe uma necessidade (motivo) que desencadeia uma ação, dando-lhe direção para alcançar um objetivo. Sendo assim, o motivo pode ser considerado um constructo criado para explicar a origem dos comportamentos dirigidos para algum objetivo (WINTERSTEIN, 1992).

O significado etimológico da palavra motivo foi extraído do latim "movere, motum", e significa aquilo que faz mover. "Em conseqüência, motivar significa provocar movimento, atividade no indivíduo" (CAMPOS, 1987, p. 108). No sentido funcional, motivo pode ser definido como:

Uma condição interna, relativamente duradoura, que leva o indivíduo ou que o predispõe a persistir num comportamento orientado para um objetivo, possibilitando a satisfação do que era visado (CAMPOS, 1987, p. 109).

E motivação, como:

O processo que se desenvolve no interior do indivíduo e o impulsiona a agir, mental ou fisicamente, em função de algo. O indivíduo motivado encontra-se disposto a despender esforços para alcançar seus objetivos (NÉRICI, 1993, p. 75).

Nérici (1993) ainda diferencia motivação de incentivo, definindo incentivo como: o estímulo exterior que visa despertar no indivíduo vontade ou interesse para algo. Logo, a definição de motivação voltada para a educação pode incluir também o conceito de incentivo, sendo entendida como: o processo de incentivo destinado a predispor os alunos ao aprendizado e à realização de esforços para alcançarem certos objetivos.

É provável que a indisciplina observada nas escolas esteja diretamente relacionada à falta de motivação dos alunos diante do fato de se verem obrigados 
a estar numa sala de aula sem entender o porquê e para quê daquilo, considerando os conteúdos inúteis ou, mesmo que sejam úteis, não compreendendo bem para que servem, como afirma Werneck (1987):

Creio que ensinamos demais e os alunos aprendem de menos e cada vez menos! Aprendem menos porque os assuntos são a cada dia mais desinteressantes, mais desligados da realidade dos fatos e os objetivos mais distantes da realidade da vida dos adolescentes (p. 13).

Conseguir que os alunos se sintam motivados para aprender é o primeiro passo para a prevenção da indisciplina, e um grande desafio para o professor e a escola. Os professores desejam alunos que saibam respeitar os seus colegas e que consigam se engajar em atividades que exijam concentração e esforço para aprender. Porém, isso não é sinônimo de aluno passivo e silencioso o tempo todo. O silêncio, tão desejado em sala de aula, nem sempre é garantia de aprendizagem, pois o aluno aprende quando participa ativamente de uma atividade, executando alguma tarefa, ouvindo as diferentes formas de percepção dos demais frente a um assunto e tendo a oportunidade de argumentar as suas idéias através de grupos de discussão ou debates. Essa participação ativa do aluno nas atividades escolares é expressão de energia e entusiasmo, fruto de uma aprendizagem significativa (NERI, 1992).

É presumível, portanto, que uma nova espécie de disciplina possa despontar em relações orientadas desta maneira: aquela que denota tenacidade, perseverança, obstinação, vontade de saber. [...] Anteriormente, disciplina evocava silenciamento, obediência, resignação. Agora, pode significar movimento, força afirmativa, vontade de transpor os obstáculos. [...] Disciplina torna-se, então, vetor de rebeldia para consigo mesmo e de estranhamento para com o mundo - qualidades fundamentais do trabalho humano de conhecer (AQUINO, 1996, p. 53).

Mas quando se questiona de quem é a responsabilidade por esta nova forma de pensar a disciplina, a partir da motivação do aluno, novamente depara-se com um impasse: o aluno deve demonstrar interesse espontâneo pelos conteúdos trabalhados em sala de aula ou compete ao professor utilizar estratégias eficientes para despertar tal motivação? 
Focalizando os alunos, Brophy (1993) caracteriza a motivação para aprender como podendo ser tanto um traço geral (motivação intrínseca), como um estado situacional (motivação extrínseca):

Como um traço geral, a motivação para aprender refere-se a uma disposição durável para valorizar o aprender como um fim em si mesmo, ou seja, a apreciar o processo e orgulhar-se com os resultados das experiências que envolvem a aquisição do conhecimento ou o desenvolvimento das habilidades. Já em situações específicas, um estado de motivação para aprender existe quando os alunos se engajam intencionalmente nas tarefas acadêmicas, buscando dominar os conceitos ou habilidades envolvidas. Os alunos que são motivados a aprender não necessariamente acham as tarefas escolares particularmente prazerosas ou excitantes, porém as abraçam seriamente, acham-nas significativas e que vale a pena esforçar-se por auferir delas os benefícios esperados (p. 200).

Observa-se que enquanto traço geral existe uma disposição durável e envolvimento efetivo por algumas matérias ou atividades. Nesse caso, o aprender é valorizado como um processo que traz grande satisfação à medida que novos conhecimentos são adquiridos. O indivíduo vê suas ações como autodeterminadas ou derivadas da vontade própria, experienciando a autonomia. A motivação está em superar os próprios limites ou atingir objetivos pessoais. Por isso, todo evento que aumentar a percepção da própria competência ou proporcionar um feedback positivo acerca da performance numa dada atividade, tenderá a aumentar a motivação intrínseca.

A motivação enquanto interesse situacional (motivação extrínseca) é explicada como sendo um estado emocional provocado por estímulos situacionais específicos que levam os alunos a se engajarem intencionalmente nas atividades escolares, procurando atingir os objetivos propostos, através da utilização de recompensas ou pressões para aumentar a ocorrência desses comportamentos. Nesse caso, a motivação está diretamente relacionada à quantidade de privação do organismo, sendo que os comportamentos emitidos para aliviar a privação são fortalecidos pelo reforçamento (SKINNER, 1991).

O reforçamento acontece quando a conseqüência de um comportamento é agradável ou desejável, ou ainda se o comportamento emitido é capaz de eliminar ou evitar algo desagradável ou doloroso. Nesse caso, é chamado de reforçamento negativo, muito freqüente em situações escolares, nas quais muitas vezes os alunos se mantêm em silêncio ou realizam atividades escolares para evitarem notas baixas, serem humilhados publicamente ou expostos ao ridículo. 
O reforçamento será mais eficiente na manutenção de comportamentos se sua apresentação for intermitente - em intervalos variáveis (SKINNER, 1991).

O problema do reforçamento é que à medida que um comportamento se vincula ao recebimento de recompensas ou à fuga de punições, é menos provável que, no futuro, na ausência dessas contingências, volte a ocorrer (RYAN; CONNELL; DECI, 1985). É o caso da maioria dos estudantes que quando estão longe dos controles escolares (notas, avaliações, prazos para entregas de trabalhos, supervisão controlada,...) deixam de se engajar em atividades de estudo.

Outra crítica à perspectiva behaviorista de associação de incentivos e recompensas ao desempenho do aluno é feita por Brophy e Rohrkemper (1981), porque embora provoque o desempenho do aluno, não é capaz de desenvolver a motivação intrínseca para aprender, pois à medida que as recompensas são atraentes, e à medida que o desempenho na tarefa é visto pelo aluno como uma forma de conseguir as recompensas e não como um fim em si mesmo, eles provavelmente irão concentrar-se em qualquer coisa que assegure tais recompensas, em vez de se concentrarem na aquisição do conhecimento e nas habilidades que a tarefa pode desenvolver.

O resultado pode ser uma mentalidade interesseira, em que os alunos busquem realizar eficientemente o mínimo necessário para conseguirem as recompensas, sem valorizarem a atividade em si, nem aspirarem a uma autêntica compreensão ou apresentarem um produto de qualidade. Alguns autores (BANDURA; SCHUNK, 1981; LEPPER; HODELL, 1989) argumentam que uma forma de amenizar os efeitos nocivos da utilização de recompensas pelo professor é associá-las não à mera execução, mas à qualidade dos trabalhos.

Convém salientar que a crítica dos autores quanto ao uso de recompensas em situação de aprendizagem recai, especificamente, na utilização de recompensas materiais sem nenhum vínculo com a valorização dos resultados obtidos através da realização da atividade (nova habilidade ou conhecimento). Por outro lado, o elogio pode produzir um efeito eficaz na motivação, pois consiste em um feedback positivo a respeito do desempenho do aluno, além de ter uma conotação afetiva. Porém, é necessário que sejam seguidos alguns critérios na sua utilização:

O elogio deve ser apresentado ao aluno individualmente, de forma justa, simples, parcimoniosa, criativa, coerente com o desempenho, buscando salientar suas peculiaridades e promovendo informações que favorecerão a percepção de competência. Além disso, deve-se enfatizar o esforço empreendido, o capricho e a persistência nos trabalhos ou o êxito obtido em tarefas difíceis (GUIMARÃES, 2001, p.53). 
O elogio fortalece o sentimento de auto-eficácia e promove a autodeterminação quando sinaliza os progressos obtidos através de uma atividade ou aquisição de um novo conhecimento, sendo capaz de sustentar o interesse do aluno, mesmo quando retirada essa contingência de reforçamento (GUIMARÃES, 2001).

Contudo, existe ainda a possibilidade da aprendizagem extrinsecamente motivada conduzir à motivação intrínseca, na qual o aluno, ao sair da escola, continuaria buscando informações para compreender o mundo em que vive, possibilitando-lhe uma atitude crítica frente aos fatos e conseqüentemente maior autonomia.

Os argumentos para essa abordagem concentram-se em torno do conceito de internalização, que se refere a uma tendência humana em transformar e assimilar os valores e as regulações externas em processos de regulação internos, tornando-os pessoalmente endossados. É um processo motivacional que permite tornar a realização de atividades desinteressantes, mais úteis para o indivíduo, sob seu próprio controle, resultando em maior integração social e intrapsíquica (GUIMARÃES, 2002, p. 51).

Nessa nova abordagem, Ryan e Deci (1985) propuseram a Teoria da Autodeterminação, na qual a motivação extrínseca passaria por quatro tipos de regulação, seguindo um continuum crescente de autonomia, até transformarse em motivação intrínseca. Os quatro tipos de regulação seriam: externa (comportamento mantido por recompensas ou punições externas), introjetada (sentimentos de culpa ou vergonha motivam a realização do comportamento esperado), identificada (identificação com o outro favorece a aceitação do que a pessoa valoriza) e integrada (o indivíduo percebe as pressões ou incentivos externos como sendo orientações para suas ações e não como coerções que controlam o seu comportamento).

Nesse sentido, o professor, como organizador da situação de aprendizagem, pode influenciar o nível de motivação dos alunos através da determinação das atividades propostas, das formas de avaliação e informações sobre o desempenho dos alunos nas atividades realizadas. Por isso, se o professor quiser promover a motivação, deve planejar tarefas adequadas ao aluno. "Adequada" aqui significa aquela que "oferece perspectivas de êxito com esforço razoável". Se a tarefa é difícil demais para o aluno, não será possível estabelecer metas que sejam razoavelmente atingíveis, e não será possível atribuir o fracasso à falta de esforço, que estará diretamente relacionada à falta de capacidade, gerando sentimentos 
de incompetência, insegurança, ansiedade e frustração; o que em cadeia acaba afetando a motivação intrínseca. Por outro lado, a realização de desafios mais fáceis favorece a percepção de auto-eficácia nas fases inicias da aquisição de novas habilidades, mas posteriormente, se for mantido o baixo nível de dificuldade das tarefas apresentadas, elas deixam de representar um desafio, podendo trazer prejuízos à motivação (NERI, 1992; BANDURA, 1993).

Mas como saber qual tarefa apresenta um nível adequado de dificuldade diante de uma turma heterogênea? Como respeitar as capacidades individuais sem estipular um tempo para a conclusão das atividades em uma classe numerosa? Embora o professor tenha que administrar algumas condições adversas para realizar o seu trabalho de forma satisfatória, Bzuneck (2001) indica algumas estratégias quanto à apresentação das atividades aos alunos:

a) dar tarefas que contenham partes relativamente fáceis para todos e partes mais difíceis, que possam ser atendidas somente pelos melhores; com isso, todos têm desafios e todos têm reais chances de acertos;

b) para aqueles que tiverem concluído por primeiro, dar atividades suplementares, de enriquecimento e interesse;

c) permitir que, por vezes, os alunos possam escolher o tipo de tarefa;

d) permitir que cada um siga seu ritmo próprio, sem qualquer pressão para que todos concluam juntos; e

e) alternar trabalhos individuais com trabalhos em pequenos grupos, desde que estes não se cristalizem e todos recebam a devida assistência (p. 129).

Convém ainda lembrar que a aprendizagem processar-se-á em melhores condições se o aluno considerar o conhecimento ou a tarefa útil na resolução de alguma necessidade, se conseguir prever que obterá êxito, estimulando seus sentimentos de competência e eficácia, e se a realização da atividade produzir alguma satisfação pessoal (TAPIA; FITA, 1999).

De acordo com Brophy e Rohrkemper (1981), toda pessoa nasce com a potencialidade (na forma de curiosidade inata) de desenvolver motivação intrínseca para aprender. Porém o quanto será desenvolvida irá depender das experiências nas quais o grau de esforço despendido na tentativa de atingir um objetivo foi proporcional ao valor atribuído àquele objetivo.

O conceito de motivação intrínseca também está relacionado com o conceito de motivação para a realização, que é definido por Winterstein (1992) 
como "o processo de competição interna, em busca da melhoria contínua da própria capacidade com o objetivo de atingir um padrão de excelência" (p. 46). Nesse caso, o aluno pode se auto-avaliar pelas observações que faz do seu próprio desempenho após realizar uma tarefa, comparando-a com uma tarefa semelhante executada anteriormente.

Os alunos que apresentam motivação intrínseca para aprender orientamse para as tarefas com expectativas de sucesso e agem na esperança de atingir o objetivo livres de distrações e de ansiedade negativa. Como não temem o fracasso, não se frustram facilmente diante dos insucessos, geralmente relacionando-os a fatores que podem ser mudados ou superados, como por exemplo: nível de dificuldade da tarefa ou necessidade de maior esforço pessoal. E quando alcançam o sucesso atribuem a si a responsabilidade do êxito, valorizando a sua capacidade e competência na realização da tarefa (LIMA, 2000).

Além desses aspectos afetivos positivos, os alunos com motivação intrínseca apresentam aspectos cognitivos voltados para a realização, como: planejamento, concentração orientada para uma meta a partir daquele conteúdo a ser aprendido ou tarefa a ser dominada (WEINER, 1984).

Tais alunos são motivados pela necessidade de conquista e em situações de aprendizagem se comportam da seguinte forma:

- $\quad$ Selecionam problemas que apresentam desafios moderados;

- $\quad$ Esforçam-se longo tempo diante de problemas difíceis;

- $\quad$ Diminuem sua motivação se alcançam êxito com muita facilidade;

- $\quad$ Respondem melhor a tarefas que implicam maiores desafios;

- Costumam conseguir melhores qualificações que outros de coeficientes intelectuais parecidos (TAPIA; FITA, 1999, p. 80).

Pelo fato dos alunos estarem livres de emoções negativas e se concentrarem nos estudos, e não em si mesmos, são capazes de persistirem por mais tempo nos casos de frustração, bem como dar conta dos problemas de modo eficaz. Tais alunos experimentam recompensas diretas e imediatas no próprio fato de se engajarem no processo de aprendizagem. Essas recompensas são: senso de controle, percepção clara do "feedback", mescla de pensamento racional e autoconsciência, ausência de preocupação consigo mesmo e uma sensação acentuada de gratificação (LIMA, 2000).

Ao contrário, os alunos "desmotivados" apresentam sintomas de desânimo adquirido ao se defrontarem com as exigências escolares. 
Quando as crianças entram na escola, tendem a enfrentar as situações de aprendizagem com avidez e confiança; o fracasso não costuma causar-lhes problemas emocionais; não parecem preocupar-se pela avaliação externa e parecem estar centradas no processo de realização da tarefa. Porém, à medida que as crianças crescem, a aparição de manifestações derrotistas aumenta (TAPIA; GARCIA-CELAY, 1996, p. 126).

Devido a experiências anteriores de fracasso, o senso de eficácia desses alunos diminui e eles passam facilmente a desistir quando lhes sobrevêm alguma dificuldade, concluindo que a tarefa era penosa demais para eles e que nenhuma perseverança ou esforço os capacitaria a conseguir êxito. Frustram-se facilmente diante dos fracassos provavelmente por terem vivenciado situações aversivas em decorrências de seus insucessos. Atribuem o fracasso à sua pouca capacidade para realizar a atividade e não se julgam capazes de modificar esse quadro. Quando obtêm êxito em uma tarefa atribuem o sucesso ao acaso, não reconhecendo a sua participação no resultado alcançado. A capacidade desses alunos de analisarem o problema e se concentrarem para produzirem possíveis soluções é comprometida por pensamentos de desesperança, antecipação de fracasso, desespero e auto-avaliação negativa (WEINER, 1984; LIMA, 2000).

Esses alunos são motivados pela necessidade de evitar o fracasso, e por isso, em situações de aprendizagem adotam os seguintes comportamentos:

a) Escolhem problemas fáceis ou irracionalmente difíceis;

b) Desanimam com os fracassos e são estimulados pelos êxitos;

c) Preferem como colegas de trabalho os que se mostram amistosos;

d) Respondem melhor a tarefas que apresentam desafios reduzidos e diante de uma aprendizagem fracionada em pequenas etapas (TAPIA; FITA, 1999, p. 81).

Os sentimentos de incompetência e baixa eficácia podem se intensificar com a experiência escolar, uma vez que os alunos devem responder a desafios intelectuais num ambiente público, em condições tais que seu desempenho não será julgado apenas subjetivamente em termos de sucesso ou fracasso, mas será submetido a uma avaliação externa, que acarreta tanto recompensa como castigo, pois nesse caso, o que conta é preservar a própria imagem diante de si mesmo e dos demais (PATTO, 1995; TAPIA; FITA, 1999).

É importante salientar que não é o fracasso inicial que diminui o interesse 
ou esforço do aluno para realizar a atividade, o que leva ao abandono da tarefa e perda da motivação é a experiência repetida de fracasso (TAPIA; GARCIACELAY, 1996). Dessa forma, para evitar a possibilidade de fracassar e receber castigo ou desaprovação social, o aluno pode se esquivar de situações de aprendizagem, através de uma atitude apática ou indisciplinada em sala de aula, sendo uma forma de se autoproteger dos sentimentos negativos de incapacidade, frustração e baixa auto-estima.

Assim sendo, para os alunos acometidos por atitudes negativas, Woolfolk e Hoy (1990) sugerem que o primeiro passo para motivá-los a aprender seria eliminar as emoções negativas diante do estudo, por meio de um programa que os levassem a um progresso contínuo e sucesso consistente ensinando-os a estabelecer metas desafiadoras, porém atingíveis, e ainda procurando atribuir o desempenho fraco à insuficiência de esforço e não à falta de capacidade. Esse cuidado deve ser tomado porque o estado motivacional de tais alunos está diretamente relacionado a um resultado auto-avaliador. Assim, o que está em jogo é a sua auto-estima, sendo que irá sentir-se culpado ou ansioso no caso de fracasso, ou autopromovido com o sucesso.

Para evitar que o aluno chegue nesse quadro de desmotivação aprendida, Tapia e Fita (1999) orientam que os professores desenvolvam junto aos seus alunos valores e atitudes positivas em relação ao estudo, concebendo a inteligência como algo modificável, enfatizando que os resultados podem ser modificados e controlados, evitando atribuí-los a causas internas.

Ryan, Connell e Deci (1985), em um experimento de laboratório, compararam os resultados no desempenho de dois grupos de pessoas em uma tarefa, de acordo com suas orientações. Para o primeiro grupo foi sugerido que a tarefa refletia tipicamente um aspecto da inteligência. Para o segundo grupo, trabalharam no sentido de que houvesse envolvimento na tarefa, simplesmente orientando-os para a atividade em si. Observaram, no primeiro grupo, menor motivação intrínseca do que no segundo. Além disso, as pessoas do primeiro grupo experimentaram mais pressão e tensão e menos interesse do que as pessoas do segundo grupo, que estavam envolvidas na tarefa. Isso sugere que os reguladores internos (como os associados a culpa, vergonha, e outros tipos de auto-reforçamento e autocontrole) não representam autodeterminação e até podem minar a motivação intrínseca e prejudicar a aprendizagem.

Ryan, Connell e Deci (1985) e Shiefele (1991), através dessa e de outras pesquisas, demonstraram que a motivação é maior quando os alunos conseguem sucesso com aquilo que eles percebem como sendo um esforço razoável em lugar de um esforço máximo e sustentado. Concluíram ainda que a atribuição de êxito em determinada tarefa, relacionando-o com fatores intrínsecos ou extrínsecos, interfere no desempenho da tarefa. Nesse sentido, verificaram que 
os alunos preferem ser considerados ao mesmo tempo como capazes e muito esforçados a apenas muito esforçados. Por isso, orientam ao professor que, ao ensinar os alunos a atribuírem o êxito às tarefas desenvolvidas, deve-se salientar tanto a sua capacidade como o seu esforço enquanto estratégia para estimular a motivação intrínseca, e em situações de fracasso, deve-se procurar relacioná-lo somente ao esforço insuficiente para estimulá-lo a persistir sem comprometer seu sentimento de auto-eficácia.

A forma como os professores organizam as atividades de aula também provoca efeitos na motivação dos alunos. Quando as atividades escolares são organizadas em um contexto competitivo, a motivação da maioria dos alunos é afetada negativamente, pois na situação de competição sempre há perdedores. Quando os trabalhos são realizados individualmente, o efeito pode ser positivo, dependendo do tipo de tarefa e das orientações fornecidas pelo professor.

A estratégia que parece produzir melhores efeitos sobre a motivação dos alunos é a realização da atividade escolar em grupos cooperativos, pois estimula o interesse dos alunos para aprender e facilita a possibilidade de obter êxito na tarefa. Porém o sucesso do grupo depende de algumas condições, tais como: o tipo de tarefa, a composição do grupo, o número de integrantes do grupo e características pessoais dos alunos. Quanto ao tipo de tarefa, as mais adequadas para produzir um efeito positivo na motivação do grupo são aquelas que admitem várias soluções, nas quais os participantes têm várias possibilidades de realizar o trabalho (TAPIA; FITA, 1999).

As mensagens transmitidas pelo professor, antes, durante e depois da realização da tarefa também exercem influência sobre a motivação dos alunos. Por isso, Tapia e Garcia-Celay (1996) sugerem que as mensagens sejam centradas nos seguintes pontos:

- $\quad$ Antes: Orientar a atenção dos sujeitos para o processo de solução, mais do que para o resultado;

- Durante: Orientar a atenção dos sujeitos para a busca e comprovação de possíveis meios de superar as dificuldades, para que evitem pensar que não podem ser superadas;

- Depois: 1) Informar sobre a correção ou incorreção do trabalho, porém centrando a atenção no processo seguido e no valor do incremento de competência conquistado, se o resultado foi um êxito.

2) Facilitar a atribuição dos resultados a causas percebidas como internas, modificáveis e controláveis, especialmente se são fracassos (p. 175). 
Quanto às características pessoais dos alunos e às interações em sala de aula, sabe-se que as relações humanas compõem-se num emaranhado de fatos, pensamentos, valores, percepções, sentimentos, ações e reações que no dia-a-dia podem transformar-se em situações de desafio para os envolvidos. O professor pode amenizar esses conflitos, demonstrando abertura para o diálogo, respeitando os pontos de vista de seus alunos, e ensinando-os a respeitarem as opiniões de outros colegas, mesmo quando há divergências.

Nesse sentido, o tipo de comunicação que o professor estabelece com seus alunos é decisivo para conseguir um clima de cooperação. Professores intimidados, que demonstram medo e se comunicam de forma defensiva costumam não serem respeitados pelos alunos. Por outro lado, professores que insultam, rotulam, criticam ou ridicularizam os alunos indisciplinados, favorecem a instalação de um clima hostil em sala de aula (SAMPAIO, 2002).

Outro erro freqüente do professor é comunicar-se com um número reduzido de alunos durante as aulas, dando atenção somente para aqueles que considera bons alunos e participam ativamente das aulas ou só para aqueles que costumam atrapalhar a ordem da classe. O ideal é distribuir a comunicação de forma a abranger o maior número possível de estudantes, e se comunicar evitando todas as formas de comparação entre os alunos, pois essa atitude pode ser danosa às crenças de auto-eficácia dos alunos, uma vez que ao serem comparados se julgam menos capazes do que os demais (BZUNECK, 2001). Na medida do possível, o professor, ao se comunicar com os alunos, deve enfatizar aspectos curriculares em detrimento de aspectos relacionados com comportamentos inadequados, porque se verifica que se o professor centrar a sua atenção nos comportamentos indisciplinados, estes passarão a ocorrer com maior freqüência, pois os alunos percebem rapidamente que esta é uma forma de chamar a atenção do professor para si (DOYLE, 1986; EMONTS; PIERON, 1988).

Por esse motivo é importante que nas primeiras manifestações de indisciplina ou provação, o professor, como autoridade, analise e resolva prontamente o problema, sem responder em um tom provocatório (SAMPAIO, 2002), considerando que "ter autoridade" não é sinônimo de "ser autoritário". O primeiro significa ter o domínio da situação, fazendo-se obedecer através da sua influência e prestígio perante os alunos, enquanto que "ser autoritário" é ser impositivo e até agressivo em algumas decisões, procurando se impor às custas do medo dos alunos de sofrer algum tipo de punição (VALLE, 1995).

Para o professor, a autoridade [...] é antes uma conquista que ele deve realizar pela sua capacidade, sua dedicação, sua ascendência e sua liderança, demonstradas no seu trato diário com os alunos (MATTOS, 1978, p. 402). 
Autoridade e respeito são atitudes que implicam em mútua aceitação entre professores e alunos, necessária não só para o bom rendimento do trabalho escolar, mas também, e principalmente, para o desenvolvimento da disciplina internalizada dos alunos.

Muitas vezes, a motivação dos alunos para se empenharem em atividades escolares e se conscientizarem de que a disciplina é um processo coletivo necessário para o desenvolvimento de um trabalho em grupo harmônico e produtivo, não depende somente do professor alterar a metodologia adotada ou definir regras de boa convivência. É preciso, também, tentar modificar o vínculo docente-aluno, a fim de promover a transformação do espaço educativo em espaço de confiança e aprendizagem.

Pelo exposto até o momento, conclui-se que o processo escolar requer que se desenvolvam simultaneamente dois traços: disciplina e motivação. Parte do que se aprende na escola é disciplina de trabalho, isto é, o hábito de fazer o que precisa ser feito - apesar de faltar vontade, sobrar desconforto e haver a atração de coisas mais interessantes. Por outro lado, se o professor conseguir desenvolver em sala de aula atividades adequadas que promovam a motivação do aluno, terá menos problemas de indisciplina, pois aluno motivado dirige sua atenção e suas ações para a execução da atividade e conseqüentemente sobra menos tempo para se envolver em atos que comprometam o desenvolvimento do trabalho e gerem indisciplina. Tarefa complexa para o professor, que precisa ser capaz de perceber as dificuldades e necessidades dos alunos, além de constantemente refletir sobre a sua prática pedagógica e planejar atividades desafiadoras e motivadoras.

\section{REFERÊNCIAS}

AQUINO, Julio Groppa. A desordem na relação professor-aluno: indisciplina, moralidade e conhecimento. In: . Indisciplina na escola: alternvativas teóricas e práticas. 7. ed. São Paulo: Summus, 1996. p. 39-55.

BANDURA, A. Perceived Self-efficacy in cognitive development and functioning. Educational Psychologist, v. 28, n. 2, p. 117-148, 1993.

BANDURA, A.; SCHUNK, D. H. Cultivating competence, self-efficacy and intrinsic teresest through proximal self-motivation. Journal of Personality and Social Psychology, Washington, v. 41, n. 33, p. 586-598, 1981. 
BROPHY, J. Conceptualizing student motivation. Educational Psychologist, Hillsdale, v. 18 , n. 3, p. 200-215, 1993.

BROPHY, J. E.; ROHRKEMPER, M. M. The influence of problem ownership on teacher's perceptions of and strategies for coping with problem student. Journal of Educational Psychology, Arlington, v. 73, n. 3, p. 295-311, 1981.

BZUNECK, José Aloyseo. As crenças de auto-eficácia e o seu papel na motivação do aluno. In: BORUCHOVITCH, Evely; BZUNECK, José Aloyseo. A motivação do aluno: contribuições da psicologia contemporânea. Petrópolis: Vozes, 2001.

CAMPOS, Dinah Martins de Souza. Psicologia da aprendizagem. Petrópolis: Vozes, 1987.

DOYLE, W. Classroom organization and management. In: research on teaching. 3. ed. New York: Mac Millan, 1986. . Handbook of

EMONTS, M; PIERON, M. Analyse des problemes de discipline dans les classes d' education physique. Revue de l'Education Physique, Liege, v. 28, n. 1, p. 33-40, 1988.

GUIMARÃES, Áurea M. Escola: espaço de violência e indisciplina. Revista eletrônica: nas Redes da Educação, UNICAMP, art. 02. Disponível em: <http://www.lite.fae. unicamp.br/revista/art02.htㅆ.>. Acesso em: 24/5/2002.

GUIMARÃES, Sueli E. R. Motivação intrínseca, extrínseca e o uso de recompensas em sala de aula. In: BORUCHOVITCH, Evely; BZUNECK, José Aloyseo. A motivação do aluno: contribuições da psicologia contemporânea. Petrópolis: Vozes, 2001.

LEPPER, M. R.; HODELL, M. Intrinsic motivation in the classroom. In: AMES, Carole; AMES, Russell (Eds.). Research on motivation in education: goals and cognitions. New York: Academic Press. v.3, p.73-105, 1989.

LIMA, Luzia Mara Silva. Motivação em sala de aula: a mola propulsora da aprendizagem. In: SISTO, Fermino Fernandes et al. Leituras de psicologia para formação de professores. Petrópolis: Vozes, 2000. p. 148-162.

MATTOS, Luiz Alves. Sumário de Didática Geral. Rio de Janeiro: Aurora, 1978.

NERI, Anita Liberalesso. A motivação do estudante? Abordagem comportamental. In: LA PUENTE, M. (Org.). Tendências contemporâneas em psicologia da educação. São Paulo: Cortez, 1992.

NÉRICI, Imídeo Giuseppe. Didática: uma introdução. São Paulo: Atlas, 1993.

PATTO, M. H. S. A produção do fracasso escolar. São Paulo: T. A. Queiros, 1995. 
RYAN, R. M.; CONNELL, J. P.; DECI, E. L. A motivational analysis of self-determination and self-regulation in education. In: AMES C.; AMES, R. (Eds.). Reserch on Motivation in Education. New York: Academic Press, v. 2, p. 16-31. 1985.

SAMPAIO, D. Indisciplina: um signo geracional? Cadernos de Organização e Gestão Escolar, v. 6, n. 2, 1999. Disponível em: <http://www.iie.min-edu.pt/biblioteca/ccoge06/ cap2.htm>. Acesso em: 28/5/2002.

SCHIEFELE, Ulrich. Interest, learning and motivation. Educational Psychologist., v.26, n.3/ 4, p.299-323, 1991.

SKINNER, B. F. Questões recentes na análise comportamental. Campinas: Papirus, 1991.

TAPIA, Jesús Alonso; FITA, Enrique Caturla. A motivação em sala da aula: o que é, como se faz. São Paulo: Loyola, 1999.

TAPIA, J. A.; GARCIA-CELAY, Ignacio Montero. Motivação e aprendizagem escolar. In: COOL, César; PALACIOS, Jesús; MARCHESI, Alvaro. Desenvolvimento psicológico e educação: psicologia da educação. v. 2. Porto Alegre: Artes Médicas, 1996.

VALLE, Maria Cristina Carreira do. Padrões de comportamento disciplinares do aluno: dificuldades associadas aos processos interacionais no cotidiano escolar. Dissertação (Mestrado em Educação) - Universidade Estadual de Londrina. Londrina, 1995.

WEINER, Bernard. Princípios para uma teoria da motivação do aluno e sua aplicação dentro de um quadro de referência atribuicional. (tradução experimental para uso restrito). In: AMES, C.; AMES, R. (Eds.). Research on Motivation in Education. New York: Academic Press, v. 1, p. 15-38. 1984.

WERNECK, Hamilton. Ensinamos demais, aprendemos de menos. Petrópolis: Vozes, 1987.

WINTERSTEIN, P. J. Motivação, educação física e esporte. Revista Paulista de Educação Física, São Paulo, v. 6, n. 1, p. 53-61, jan./jun. 1992.

WOOLFOLK, A. E.; HOY, W. K. Prospective teachers' sense of efficacy and beliefs about control. Journal of Educational Psychology, v. 82, n. 1, p. 81-91, 1990.

Texto recebido em 28 de março de 2005. Texto aprovado em 17 de janeiro de 2006. 